\title{
Effect of Climate Change on Food and Water Borne Diseases Outbreak: A Mini Review
}

\author{
Lamenew Fenta \\ Assosa University, Department of Biology, Ethiopia \\ Ameha Kebede \\ Haramaya University, Department of Biology, Ethiopia
}

\begin{abstract}
Climate changes include alternations in one or more climate variables including temperature, precipitation, wind, and sunshine. These changes may impact the survival, reproduction, or distribution of disease pathogens and hosts, as well as the availability and means of their transmission environment. The health effects of such impacts tend to reveal as shifts in the geographic and seasonal patterns of human infectious diseases, and as changes in their outbreak frequency and severity. There are many pathways through which climate related factors may impact food safety including: changes in temperature and precipitation patterns, increased frequency and intensity of extreme weather events, ocean warming and acidification, and changes in the transport pathways of complex contaminants. Temperature increases and changes in rainfall patterns have an impact on the persistence and patterns of occurrence of bacteria, viruses, parasites and fungi and the patterns of their corresponding foodborne diseases. Extreme weather events such as floods and droughts lead to contamination of soil, agricultural lands, water and food and animal feed with pathogens, chemicals and other hazardous substances, originating from sewage, agriculture and industrial settings. Emergency situations after natural disasters are of special concern for water and food sanitation. Ocean warming and climate change related acidification and changes in ocean salinity and precipitation also affect the biochemical properties of water, along with water microflora.
\end{abstract}

Keywords: Climate change, Disease, Food borne, Outbreak, Water borne

DOI: $10.7176 / \mathrm{FSQM} / 88-02$

Publication date:July $31^{\text {st }} 2019$

\section{Introduction}

Climate change in the $21^{\text {st }}$ century is a global phenomenon and become more variable with extreme weather events increasing in regularity and intensity (IPCC5, 2013). The term 'climate change' refers to a statistically significant variation in either the mean state of the climate or in its variability, persisting for an extended period (typically decades or longer). Climate change may be due to natural processes, or to persistent anthropogenic changes in the composition of the atmosphere or in land use. According to the United Nations Framework Convention on Climate Change (UNFCCC) 'climate change is defined as a change of climate which is attributed directly or indirectly to human activity that alters the composition of the global atmosphere and which is in addition to natural climate variability observed over comparable time periods (Intergovernmental Panel on Climate Change, 2001). There is now agreement among most climate scientists that the globe has, on average, already begun to warm, probably as a result of increased emissions of greenhouse gases associated with industrialization and altered land-use patterns (Albritton et al., 2001). Climatic conditions and weather patterns have many consequences for human physiology, health and survival. However, most climate-related health risks are mediated via the influences of climatic changes and shorter-term weather fluctuations on food yields, water flows, patterns of infectious diseases and the movement or displacement of groups and populations. When climatic conditions change over time, then changes in patterns of health risks and in population health profiles should be expected (Michael and Lindgren, 2011). Climate change is not just another discrete environmental health 'hazard'. It differs qualitatively from the very familiar category of locally acting, toxicological, environmental health hazards (such as pesticides, heavy metals, asbestos, ionizing radiation). Climate change is a complex phenomenon entailing altered conditions and processes that can alter the rates, ranges, seasonality and patterns of injury, disease and death. Except for some direct effects on health from increases in extreme weather conditions and events, it is not the climate itself that affects human health; rather, the health consequences result from the environmental, ecological and social impacts of a changing climate (Michael and Lindgren, 2011). The major impacts of climate change include severe floods, frequent and prolonged droughts, an increase in temperature, unusual regional weather patterns, more severe storms, heat waves, rising sea levels, thawing permafrost, more frequent droughts, acidification of oceans, change in nutrient loads, and altered ocean circulation, crop failure, loss of livestock, lower water availability and quality and an increase in vector and waterborne diseases (Githeko et al., 2000; Patz et al., 2005; Solomon et al., 2007; Miraglia et al., 2009). Diseases associated with climate change are estimated already to comprise $4.6 \%$ of all environmental risks and hazards. It has been estimated that climate change in the year 2000 contributed to about $2.4 \%$ of all diarrhea outbreaks in the world, $6 \%$ of malaria outbreaks in certain developing countries, and $7 \%$ of the episodes of dengue fever in some 
industrial countries (Luma, 2014). In total, the estimates show that climate change related mortalities has been $0.3 \%$, whereas the related burden of disease has been $0.4 \%$ (Kendrovski and Gjorgjev, 2012). From 1906 to 2005 , global average temperature has warmed by $0.74^{\circ} \mathrm{C}$, and since 1961 , sea level has risen on average by approximately $2 \mathrm{~mm}$ per year. Arctic sea ice extent has declined by $7.4 \%$ per decade, and snow cover and glaciers have diminished in both hemispheres (Mills et al., 2010).

Although the impacts of climate change are global, the most vulnerable are the poor and marginalized people from developing countries who depend most directly on their ecosystems for survival. These are the same people who have the least capacity to adapt to the rapid changes that are affecting their environment (WHO, 2008), who do not have access to adequate safe water, adequate sanitation and lack access to land, credit or knowledge.

Climate change-related impacts on the ecosystems are likely to affect population by creating favourable conditions for disease vectors or disease pathogens as well as placing the communities at high risk of malnutrition, diarrheal diseases and other environmental health effects attributable to climate change (Ebi et al., 2007). There is evidence to show that climate change affect the occurrence and distribution of human diseases and malnutrition. Changes in the frequency and spread of infectious diseases are some of the most widely documented potential effects of climate change, and could have significant consequences for human health as well as economic and societal impacts (Chan et al., 1999).

In the USA the economic burden of food borne illness has been estimated to be $\$ 14$ billion/year (Batz et al., 2012) and when the etiological agents of food borne outbreaks have been identified, bacteria have been found to be responsible for $39 \%$, viruses $59 \%$ and parasites $2 \%$ of the outbreak with the majority of the economic cost associated with five pathogens: Salmonella $\mathrm{sp}$, Campylobacter sp, Listeria monocytogenes, Toxoplasma gondii and norovirus (Scallan et al., 2011) with Salmonella being the most commonly reported bacterial pathogen. In England and Wales the economic burden in 2006 was estimated to be $£ 1.5$ billion (FAO, 2008) with Campylobacter sp. being the most common bacterial cause of food poisoning (EFSA/ECDC, 2015). In response to global warming the seasonality and geographic range of food borne disease pathogens is expected to expand and additional food borne outbreaks are expected to occur as a results of extreme weather events. Correlations between meteorological parameters and the behaviour of food borne pathogens have been made (Rose et al., 2001) and these can be used as a basis to speculate on the potential impact of climate change on future patterns at a more local level.

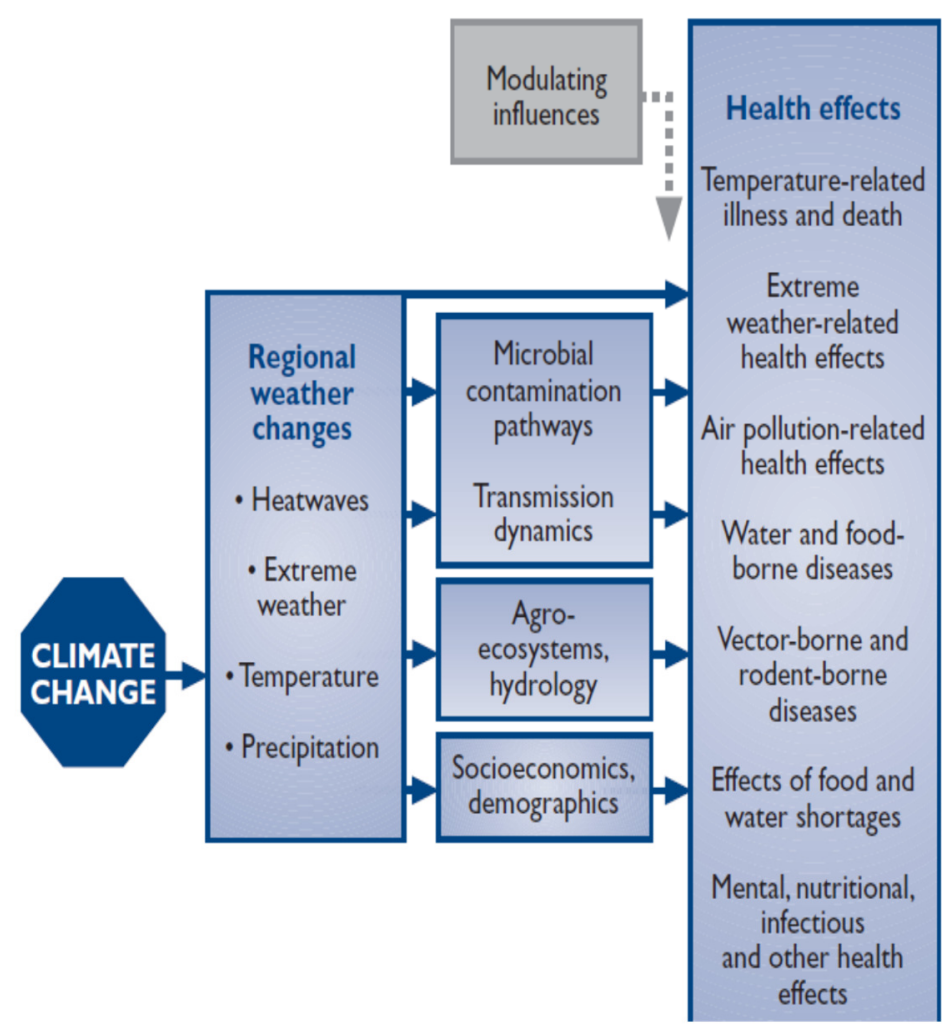

Fig. 1. Climate Change and Human Health: Risks and Responses (WHO, 2003)

\section{Climate and disease}

Climate is a key determinant of health. Climate constrains the range of infectious diseases, while weather affects 
the timing and intensity of outbreaks (Singh, 2001). A long term warming trend is encouraging the geographic expansion of several important infections (D'Souza, 2004), while extreme weather events are spawning 'clusters' of disease outbreaks and sparking a series of 'surprises' (McMichael et al., 2006; Ebi, 2006). Ecological changes and economic inequities strongly influence disease patterns. But a warming and unstable climate is playing an ever-increasing role in driving the global emergence, resurgence and redistribution of infectious diseases. Climate change could affect existing pathogens or lead to the emergence of new Pathogens in food through effects on animal husbandry and animal-to-animal transmission, pathogen survival, and other mechanisms (Tirado et al., 2010). Climate change may increase the demand for irrigation water, elevating pathogen risks by manure and sewage contamination. Particularly, temperature increase and changes in precipitation pattern have a close relationship not only with the fate and transport of enteric bacteria but also with their growth and survival. For instance, Liu et al. (2013) in a study of the impacts of climate change on the microbial safety of pre harvest leafy green vegetables predicted that the contamination risks by pathogenic Escherichia coli and Salmonella are likely to increase. The pathogens probably to be affected by climate change are those with low-infective doses (e.g., Shigella, E. coli serovars) where small changes in distribution or abundance could lead to large outbreaks. Other certainly affected pathogens are those with significant persistence in the environment (e.g., enteric viruses and parasitic protozoa) (FAO, 2008). Pathogens with good stress tolerance responses to temperature and pH (e.g., Salmonella) may also compete better against other pathogens under climate change. Another aspect to consider is that gene transfer between bacterial species is a common contributor to pathogenicity and antibiotic resistance and is likely to be impacted by changes in the environment caused by climate change. Important environmental factors include temperature, precipitation and humidity. Changes in temperature, precipitation patterns, and extreme climatic events could ultimately lead to the spread of diverse human diseases (Kinney, 2008). Rising temperatures can increase the concentrations of unhealthy air pollutants, smog, pollen pollution, and wildfire smoke, all these can bring about diverse symptoms such as eye irritation, headache, nasal stuffiness, wheezing, skin irritation, coughing, and chest pain (Dreschler et al., 2006). Immunocompromised individuals especially, young children, the elderly, and those with respiratory problems (such as asthma, emphysema, and bronchitis), are vulnerable to the effects of climate change (Kim et al., 2013). Several possible transmission components include pathogen (viral, bacterial, etc.), vector (mosquito, snail, etc.), non-biological physical vehicle (water, soil, etc.), non-human reservoir (mice, deer, etc.) and human host. Epidemiologists classify infectious diseases broadly as anthroponoses or zoonoses, depending on the natural reservoir of the pathogen; and direct or indirect, depending on the mode of transmission of the pathogen.

\subsection{Directly transmitted diseases Anthroponoses}

Directly transmitted anthroponoses include diseases in which the pathogen normally is transmitted directly between two human hosts through physical contact or droplet exposure. The transmission cycle of these diseases comprises two elements: pathogen and human host. Generally, these diseases are least likely to be influenced by climatic factors since the agent spends little to no time outside the human host. These diseases are susceptible to changes in human behaviour, such as crowding and inadequate sanitation that may result from altered land use caused by climatic changes. Examples of directly transmitted anthroponoses include measles, TB, and sexually transmitted infections such as HIV, herpes and syphilis (Wilson, 2001).

\section{Zoonoses}

Directly transmitted zoonoses are similar to directly transmitted anthroponoses in that, the pathogen is transmitted though physical contact or droplet exposure between reservoirs. However, these agents are spread naturally among animal reservoirs and the infection of humans is considered to be a result of an accidental human encounter. The persistence of these pathogens in nature is largely dependent on the interaction of the animal reservoir and external environment which can impact the rate of transmission, host immunity, rate of reproduction, and species death, rendering these diseases more susceptible to effects of climate variability. Hantavirus is a directly transmitted zoonosis that is naturally maintained in rodent reservoirs and can be transmitted to humans at times of increased local abundance of the reservoir. Rabies is another directly transmitted zoonosis that naturally infects small mammals, although with very little opportunity for widespread transmission, being highly pathogenic to its vertebrate host (Wilson, 2001). Several of today's anthropogenic diseases, e.g. TB and HIV, originally emerged from animals.

\subsection{Indirectly transmitted diseases}

Indirectly transmitted anthroponoses are a class of diseases defined by pathogen transmission between two human hosts by either a physical vehicle (soil) or a biological vector (tick). These diseases require three components for a complete transmission cycle: the pathogen, the physical vehicle or biological vector, and the human host. Most vectors require a blood meal from the vertebrate host in order to sustain life and reproduce. Indirectly transmitted anthroponoses include malaria and dengue fever, whereby the respective malaria parasite and the dengue virus are 
transmitted between human hosts by mosquito vectors (vector-borne disease). Indirectly transmitted water-borne anthroponoses are susceptible to climatic factors because the pathogens exist in the external environment during part of their life cycles. Flooding may result in the contamination of water supplies or the reproduction rate of the pathogen may be influenced by ambient air temperatures (Wilson, 2001). Cholera is an indirectly transmitted water-borne anthroponose that is transmitted by a water vehicle: the bacteria (Vibrio cholerae) reside in marine ecosystems by attaching to zooplankton. Survival of these small crustaceans in turn depends on the abundance of their food supply, phytoplankton. Phytoplankton populations tend to increase (bloom) when ocean temperatures are warm. As a result of these ecological relationships, cholera outbreaks occur when ocean surface temperatures rise (Colwell, 1996).

Indirectly transmitted zoonoses are similar to indirectly transmitted anthroponoses except that the natural cycle of transmission occurs between nonhuman vertebrates: humans are infected due to accidental encounters with an infected vehicle or vector. This class of disease involves four components in the transmission cycle: the pathogen, biological vector or physical vehicle, animal reservoir, and human host. These diseases are highly susceptible to a combination of ecological and climatic factors because of the numerous components in the transmission cycle, and the interaction of each of these with the external environment (Wilson, 2001).

Complex cycles of disease transmission also exist for several diseases which cannot be classified simply by method of transmission or natural reservoir. Such a disease is Rift Valley fever where the virus is primarily a zoonotic disease, spread among vertebrate hosts by the mosquito species Aedes. Primarily under flood conditions, Culex mosquitoes may feed upon infected ungulate hosts. This vector is referred to as a bridge species because it feeds on humans also, resulting in spread of the virus outside its normal zoonotic cycle (Wilson, 2001).

\section{Anthroponoses}
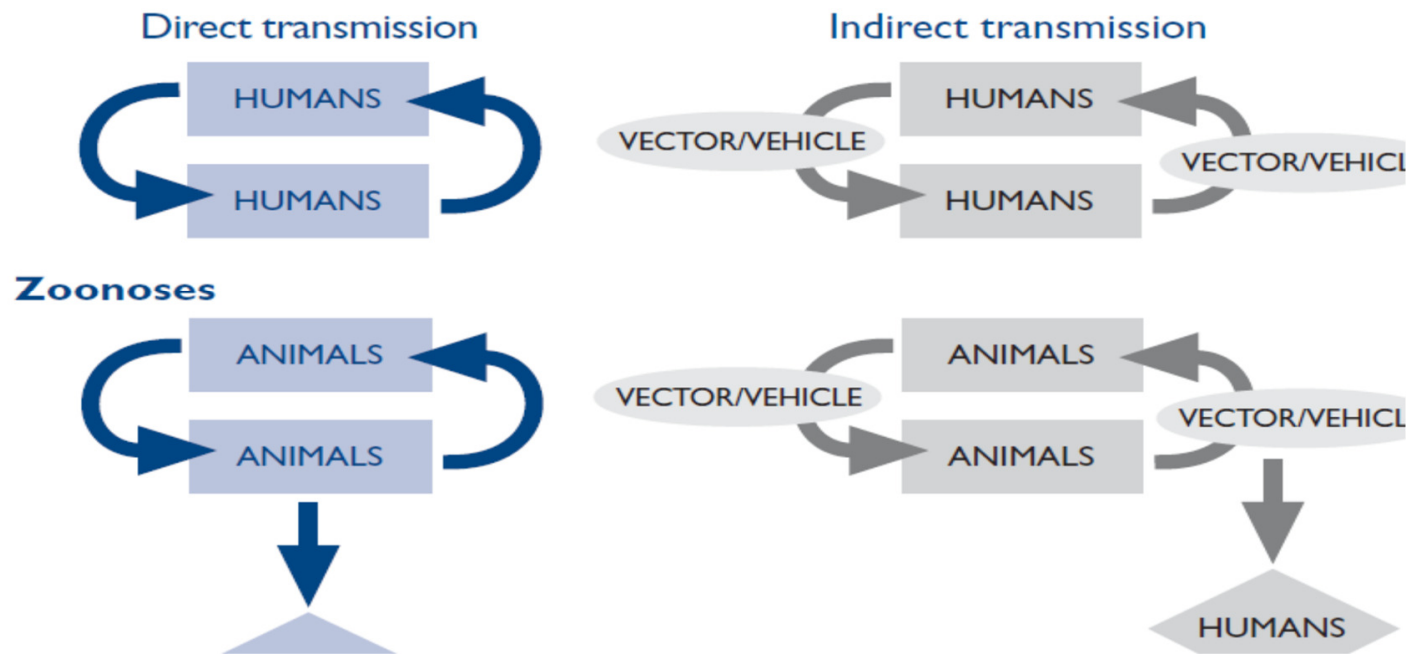

Fig. 2. Four main types of transmission cycle for infectious diseases (Wilson, 2001)

\section{Climate change and food borne disease}

\subsection{Food Borne Disease (FBDs)}

Food-borne diseases are a major public health concern worldwide. WHO defines food-borne disease (FBD) as "disease of infectious or toxic nature caused by, or thought to be caused by, the consumption of food or water. Annually, an estimated 76 million illnesses, 325,000 hospitalizations, and 5,000 deaths are caused by food-borne diseases in the United States (Scallan, 20113). Among these cases, 31 known pathogens cause 9.4 million illnesses, 56,000 hospitalizations, and 1300 deaths. Using data from 2000-2008, researchers estimated that pathogens that were implicated in most FBD were norovirus (5.5 million, 58\%), nontyphoidal Salmonella spp. (1.0 million, 11\%), Clostrodium perfringens (1.0 million, 10\%), and Campylobacter spp. (0.8 million, 9\%). Among many food-borne pathogens, nontyphoidal Salmonella spp. and Campylobacter spp. are the leading causes of FBD in the United States, England, and Australia (Scallan, 2011).

\subsection{Effects of temperature and precipitation on major food borne diseases}

Environmental determinants are drivers of food, water borne and vector borne diseases. Climatic conditions can influence the fate and transport of pathogens, as well as their viability, stability, and reproduction rates in the environment. Elevated temperatures increase the replication cycles of most food- and waterborne pathogens. Temperature measurements are among the best climatic data available to date, with an extensive monitoring network throughout the world (Semenza et al., 2012).

High temperatures favour the multiplication of some pathogenic micro-organisms in food. Foodborne 
diarrhoeal diseases that have been identified as a priority for more routine monitoring because of changing climate conditions include salmonellosis, campylobacteriosis, vibriosis, listeriosis, other bacterial infections, parasitic infections, viral diarrhoeal syndromes (ECDC, 2007).

Table 1. top five pathogens causing food borne illness resulting in death

\begin{tabular}{|l|c|c|c|}
\hline Pathogen & $\begin{array}{c}\text { Estimated annual number of } \\
\text { deaths }\end{array}$ & $90 \%$ Credible Interval & $\%$ \\
\hline Salmonella, nontyphoidal & 378 & $0-1,011$ & 28 \\
\hline Toxoplasma gondii & 327 & $200-482$ & 19 \\
\hline Listeriamonocytogenes & 255 & $0-733$ & 11 \\
\hline Norovirus & 149 & $84-237$ & 6 \\
\hline Campylobacterspp. & 76 & $0-332$ & 88 \\
\hline \multicolumn{1}{c}{ Subtotal } & & & 24 \\
\hline
\end{tabular}

\section{Salmonellosis}

Source: (Scallan et al., 2011)

Salmonellosis is a major foodborne illness globally, incurring substantial health and economic costs. It is a bacterial infection typically acquired through consumption of contaminated poultry meat and eggs, although cases have been linked to raw milk and fresh produce including melons and sprouts. A recent study estimated that approximately 93.8 million human cases of gastroenteritis and 155,000 deaths occur due to Salmonella infection around the world each year (Luma et al., 2014). In the United States alone, Salmonella causes an estimated 1.4 million human cases, 15,000 hospitalizations, and more than 400 deaths annually (Callaway et al., 2008). Emergence or resurgence of numerous infectious diseases are strongly influenced by environmental factors such as climate or land use change (Mills et al., 2010). Weather is a key influence on salmonellosis. Higher temperatures enable quicker replication of Salmonella, increasing the contamination risk throughout the paddock-to-plate chain. According to Stephen and Barnett (2016), higher daily mean temperature and precipitation increase the risk of contracting salmonellosis. A $5^{\circ} \mathrm{C}$ increase in mean temperature was associated with a $59.4 \%$ increase in salmonellosis cases while a $10 \mathrm{~mm}$ increase in precipitation increased cases by $14.6 \%$. Precipitation likely increases salmonellosis incidence shortly after a rainfall event by increasing pathogen loads in household rainwater tanks through run-off from gutters or in surface waters which individuals may have recreational contact with (Ahmed and Goonetilleke, 2010). More over a high incidence of salmonella infection was reported in summer (July-September) in Mississipi in a seasonal trend of 2002-2011 when there is high temperature record (Luma et al., 2014; Joseph et al., 2016).

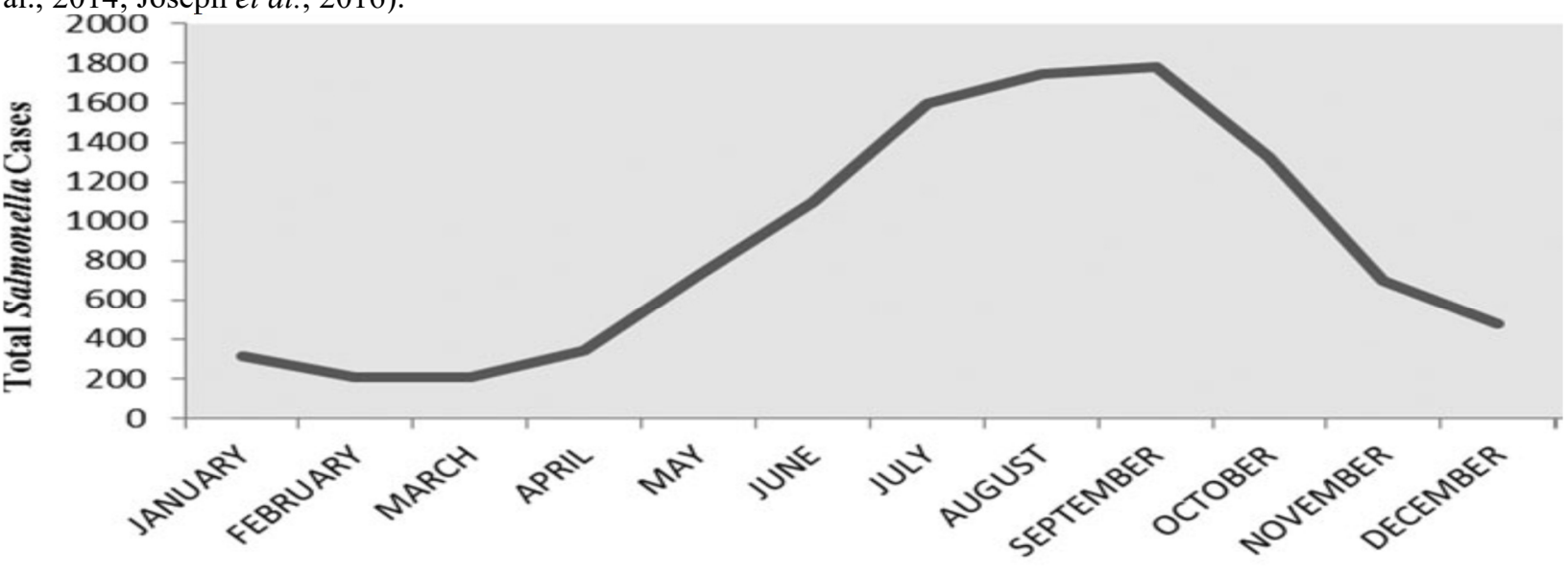

MONTH

Fig.3. Total monthly Salmonella cases in Mississippi from 2002 to 2011 . Highest rates of Salmonella were observed during the summer (Luma et al., 2014). 


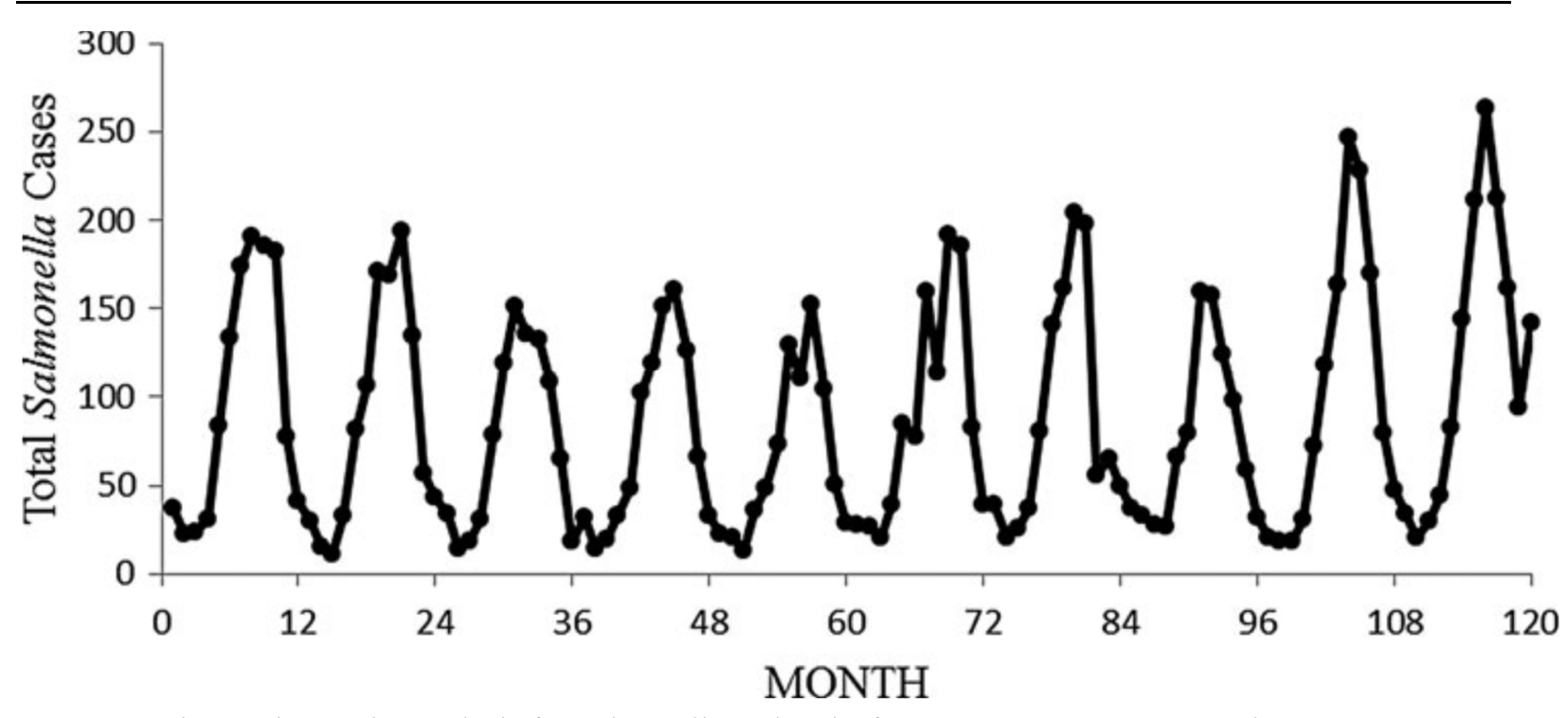

Fig. 4. Time series analysis for Salmonella outbreaks from January 2002 to December 2011.

(Luma et al., 2014).

\section{Campylobacteriosis}

Campylobacter has become the leading cause of enteric zoonotic infections in most developed and developing countries, and the incidence appears to be increasing. It is estimated that approximately $80 \%$ of cases are domestically acquired (Patrick et al., 2004). Campylobacter is commonly found in domesticated animals, including poultry, cattle, pigs, sheep, cats, and dogs, and in migratory birds, such as ducks and seagulls. Campylobacteriosis incidence was linked to mean temperatures. High ambient temperatures and relatively low humidity were associated with an incidence increase, but showed a time lag of 2-3 weeks (Kovats et al., 2005; Patrick et al., 2004). The steepest increase in incidence in humans occurs at average temperatures between 8 and $13^{\circ} \mathrm{C}$, with a smaller increase at temperatures above $13^{\circ} \mathrm{C}$ (Patrick et al., 2004). Similarly, a study conducted in Denmark revealed that large increase in incidence was seen at temperatures between 13 and $20^{\circ} \mathrm{C}$, followed by a smaller increase at higher temperatures (Patrick et al., 2004). Environmental measurements of Campylobacter in raw sewage display a seasonal pattern related to campylobacteriosis incidence, with a peak occurrences in the summer (Jones, 2001). 

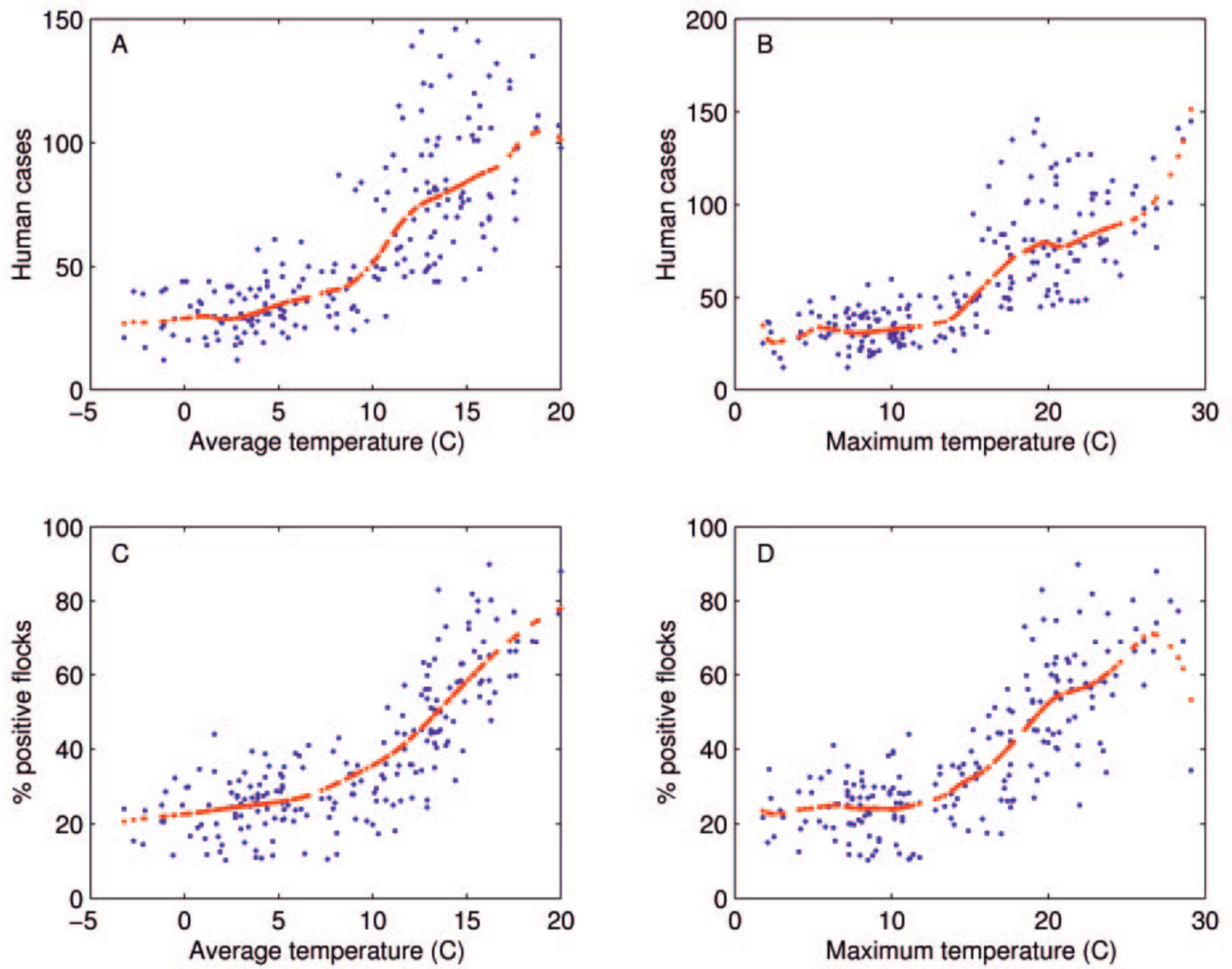

Fig.5. Impact of temperature on human campylobacteriosis incidence and the percentage of Campylobacterinfected broiler flock at slaughter. The blue dots indicate observations, and the red dots indicate estimates (Patrich et al., 2004).

Precipitation in early spring can trigger campylobacteriosis outbreaks (WHO, 2008), which could in part explain the seasonal increase in sporadic cases during May. Campylobacter sp. outbreaks occur more often in rural areas, where households often tend to be supplied by private water sources, which tend to be more susceptible to contamination during extreme weather events (Hearnden et al., 2003; Pebody et al., 1997). In Sweden, a positive association was found between Campylobacter incidence and average pipeline length per person for populations not connected to public water supplies (Nygard et al., 2004).

\section{Listeriosis}

Listeriosis in humans is caused by the bacterium Listeria monocytogenes and is characterized by meningitis and sepsis, 3-70 days $(M=3$ weeks) after infection. In 2007, there were 1,635 reported cases across 29 European countries, the majorities $(56 \%)$ of which were reported in individuals over 65 years of age (ECDC, 2010). As Listeria sp. are ubiquitous in the environment and grow in a wide temperature range, they are present year round and can be detected worldwide regardless of climatic zone. Thus, it is unlikely that changes in season will directly affect the occurrence of Listeria sp. in their habitat. However, indirect transmission pathways may be affected. Listeria sp. grow within a wide temperature range but no terms for air temperature or water temperature were found for Listeria sp. (Semenza et al., 2012).

Comprehensive analysis of climatic determinants for Listeria sp. revealed a lack of associations as well as a number of data gaps. No information was available about temperature thresholds, extreme precipitation events, or temperature limits. Data was also lacking on seasonality, floods, droughts, storms, irrigation, or recreational activities (Semenza et al., 2012). 


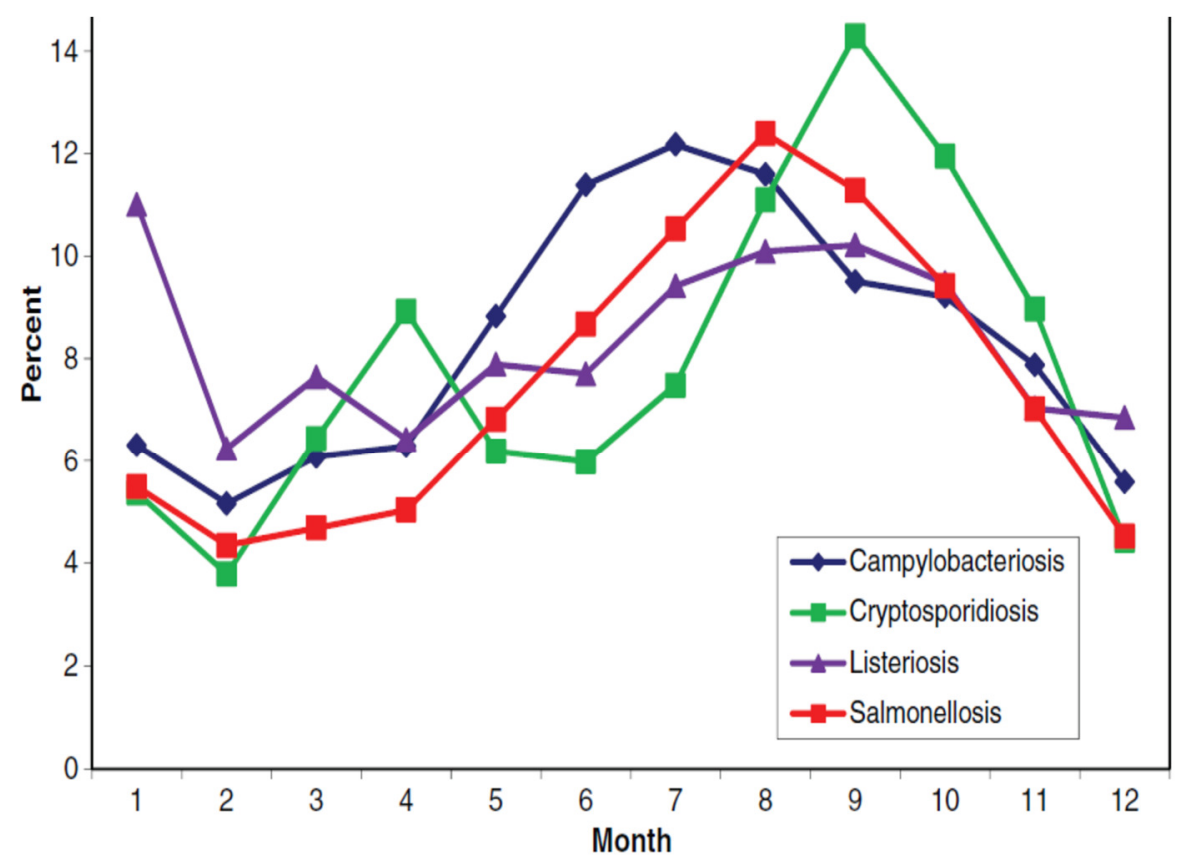

Fig. 6. Seasonal distribution of Campylobacteriosis,Cryptosporidiosis, Listeriosis, and Salmonellosis (Semenza et al., 2012)

\section{Climate change and water borne diseases}

According to Edwards (2015) explanation, waterborne outbreaks are highly correlated with extreme events like increase in water temperature, precipitation frequency and intensity, and changes in coastal ecosystem health $(\mathrm{pH}$, salinity, nutrient and contamination runoff). The effects are pathogen and pollutant specific. Waterborne microorganisms include: Protozoa (cryptosporidiosis), Parasites (shistosomiasis), Bacteria (Cholera and legionella), Viruses (gastroenteritis), and Amoebas (meningoencephalitis).

Waterborne pathogens of human and animal faecal origin include a high number of viruses, bacteria and parasitic protozoa. Human exposure to water-borne infections can occur as a result of contact with contaminated drinking water, recreational water, coastal water, or food. Exposure may be a consequence of human processes (improper disposal of sewage wastes) or weather events. Rainfall patterns can influence the transport and dissemination of infectious agents while temperature can affect their growth and survival (Rose, 2001).

\subsection{Effect of Heavy rainfall and floods}

Heavy rains can contaminate watersheds by transporting human and animal faecal products and other wastes in the groundwater. Evidence of water contamination following heavy rains has been documented for cryptosporidium, giardia, and E.coli (Menne, 2011; Nie, 2009). This type of event may be increased in conditions of high soil saturation due to more efficient microbial transport (Rosen, 2000). At the other extreme, water shortages in developing countries have been associated with increases in diarrhoeal disease outbreaks that are likely attributed to improper hygiene (Hilscherova et al ., 2007).

More frequent and intense heavy rainfall/floods cause higher pathogen concentrations in natural waters which will generally be reflected in worse quality of drinking and bathing waters, crops and shellfish. Indeed, heavy rainfall/floods can cause over-flooding of sewage treatment plants, runoff of animal dejections and manure, remobilization and redistribution of contaminated sediments (Menne, 2011). Enhanced environmental levels of pathogenic microorganisms may result in increased incidence of diseases and occurrence of new ones (Boxall et $a l ., 2009)$. In general it is expected that zoonotic infections may expand due to an increased washing into water of wild animal and livestock faeces.

Floods and hurricanes, destroying the water distribution system and mixing drinking and waste waters, can have a significant impact also on the diffusion of cholera, caused by the naturally occurring $V$. cholerae. The disease is one of the most severe forms of waterborne diarrheal disease, especially for developing countries, where outbreaks occur seasonally and are associated with poverty and use of poor sanitation and unsafe water (WHO, 2012).

There are several examples of waterborne diseases outbreaks associated to excessive rainfall (Howe et al., 2002 and Kistemann, 2002). The largest reported waterborne disease outbreak in the United States, due to the presence of Cryptosporidium cists in drinking water, occurred in Milwaukee in 1993 and was related to heavy 
rainfall and associated runoff and consequent contamination of Milwaukee lake, the source of the waterworks of the area. It resulted in the deaths of 54 people and more than 403,000 ill (MacKenzie, 1994 and Hoxie, 1997). Contamination of groundwater after flooding has been associated to additional disease outbreaks like Acanthamoeba keratitis in Iowa (USA) (Hunter, 2003). Cryptosporidiosis cases in England and Wales were positively associated with maximum river flow (Lake, 2005). In the US, Curriero et al, (2001) reported a statistically significant association between excess rainfall and waterborne disease outbreaks over a long period of time. In the European Union, in 2007, only 17 waterborne outbreaks were reported by eight countries, clearly indicating an under-reporting; they involved 10912 cases, with 232 hospitalizations. The main microorganisms involved were Campylobacter, norovirus, Giardia and Cyptosporidium (Kistemann, 2002).

\subsection{Effect of Temperature}

Temperature has a positive association with water borne diseases outbreak. Increasing temperatures may lengthen the seasonality or alter the geographical distribution of water-borne diseases. In the marine environment, warm temperatures create favourable conditions for red tides (blooms of toxic algae) which can increase the incidence of shellfish poisoning (Hurst, 2007). Increasing sea surface temperatures can indirectly influence the viability of enteric pathogens such as Vibrio cholerae by increasing their reservoir's food supply (Evans et al., 2005). Warmer pond and rivers increase the incidence of cholera through the faster growth rate of the pathogen in aquatic environments (Koelle et al., 2005). Increasing temperature could also favor the growth of some pathogenic indigenous bacteria, like Vibrio parahaemolyticus, $V$. vulnificus and $V$. alginolyticus, which are already among the most common etiological agents responsible for diseases transmitted by seafood consumption in US (Funari, 2012).

\subsection{Effect of Droughts}

The impacts of drought on human health due to shortage of water are dramatic and include deaths, malnutrition, increase in infectious diseases (Menne , 2000). These effects are associated with worsening hygienic conditions, higher probability of microbial contamination of drinking water due to infiltration of organic material along the distribution system when pressure drops, higher re-use of wastewaters in agriculture, with consequent contamination of fresh vegetables, unsafe use of untreated water. Additionally, water shortages may increase the likelihood of multiple uses of a water body (e.g., for cleaning, bathing, and drinking) with a consequent increase of the risk of microbial contamination and human exposure to pathogens (Lipp et al., 2002).

Periods of droughts followed by short intense rainfall can cause peaks of surface water contamination. Outbreaks of cryptosporidiosis have been associated to contamination of drinking water supplied by surface water, due to intense rainfall after very long and unusual drought periods, in Japan and Oregon (Yamamoto et al, 2000). The largest reported outbreak of E. coli O157:H7 occurred at a fairground in the state of New York in September 1999 and was linked to contaminated well water. This outbreak resulted from unusually heavy rainfall, which was preceded by a drought (Patz et al., 2000). River-bed sediments represent an important microorganisms reservoir in dry areas, like the Mediterranean, where long dry periods are interrupted by flashfloods, transporting most of them downstream, up to coastal waters (Chu et al., 2011). Similarly, in UK, an outbreak of Cryptosporidium, due to contamination of the borehole used as a source of drinking water was recorded when unusually very strong rainfall followed a long dry period (Willocks et al., 1998).

\section{Climate change and Vector-borne diseases (VBDs)}

Climate change can exert an influence on transmission cycles and the occurrence of vector-borne diseases (VBD) (e.g., malaria, schistosomiasis, onchocerciasis, trypanosomiasis, filariasis, leishmaniasis, plague, Rift Valley fever, etc.). VBD is mainly transmitted by the bite of infected arthropod species such as mosquitoes, ticks, triatomine bugs, sandflies, and blackflies (Confalonieri et al., 2007). Because arthropod vectors are cold-blooded (ectothermic), the biology and ecology of vectors and intermediate hosts are affected by a number of factors (temporal and spatial changes in temperature, precipitation, and humidity). Changes in survival and the reproduction rates of vectors in turn can influence habitat suitability, distribution, abundance, intensity, and temporal patterns of vector activity (particularly biting rates) (Rogers ,2006). Plasmodium falciparum malaria epidemics and Rift Valley fever were observed in Kenya from 1997-1998 due to a short-term increase in temperature and rainfall as an effect of El Nino (Wanjala et al., 2011). VBD is found to be transmitted mainly by mosquito species. As adult female mosquitoes digest blood faster and feed more frequently, they can increase transmission intensity in warmer climates (Hopp, 2001).

In addition, mosquito larvae take a relatively short time to mature at high temperatures. Hence, more offspring can be produced during the transmission period. At the same time with rising temperature, malaria parasites and viruses can complete extrinsic incubation within the female mosquito in a short time (Alonso, 2011).

The transmission rate of dengue was also found to increase as observed from $2 \circ \mathrm{C}$ rise in temperature in northern India (Dhiman et al., 2010). This was because rising temperatures shortened the extrinsic incubation period of the virus as well as the development time and the gonotrophic cycle of the mosquito, resulting in an 
increased likelihood of dengue transmission (Lambrechts et al., 2011). As a result of increases in heat, precipitation, and humidity, nearly 4000 cases of imported and locally transmitted dengue fever were reported in the United States between 1995 and 2005 (Patz et al., 2005). However, several other factors (such as changes in land use, population density, and human behavior) can also influence the occurrence pattern of VBD as well as the extent of its infection (Rogers, 2006).

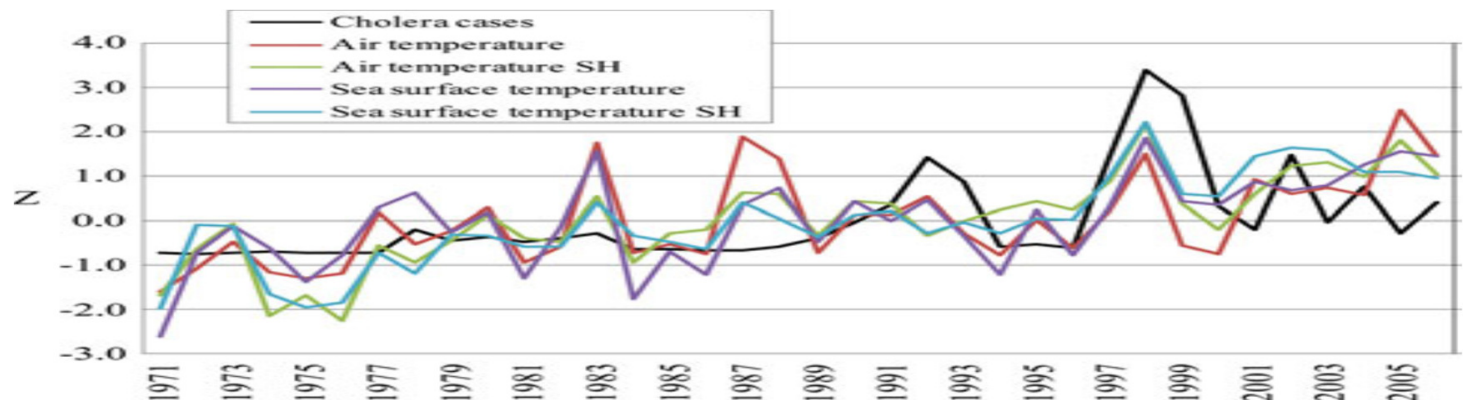

Fig. 7. Annual standardized values of cholera incidence, air temperature (local and hemispheric scales) and sea surface temperature (local and hemispheric scales), 1971-2006. (Paz, 2014)

\section{Summary}

Climate changes include alternations in one or more climate variables including temperature, precipitation, wind, and sunshine. These changes may impact the survival, reproduction, or distribution of disease pathogens and hosts, as well as the availability and means of their transmission environment. The health effects of such impacts tend to reveal as shifts in the geographic and seasonal patterns of human infectious diseases, and as changes in their outbreak frequency and severity.

There are many pathways through which climate related factors may impact food safety including: changes in temperature and precipitation patterns, increased frequency and intensity of extreme weather events, ocean warming and acidification, and changes in the transport pathways of complex contaminants. Temperature increases and changes in rainfall patterns have an impact on the persistence and patterns of occurrence of bacteria, viruses, parasites and fungi and the patterns of their corresponding foodborne diseases. Such changes also have an impact on microbial ecology and growth, plant and animal physiology and host susceptibility which may result in the emergence, redistribution and changes in the incidence and intensity of plant and animal diseases and pest infestations, all of which could impact foodborne diseases (FAO, 2008).

Extreme weather events such as floods and droughts lead to contamination of soil, agricultural lands, water and food and animal feed with pathogens, chemicals and other hazardous substances, originating from sewage, agriculture and industrial settings. Emergency situations after natural disasters are of special concern for water and food sanitation. Ocean warming and climate change related acidification and changes in ocean salinity and precipitation also affect the biochemical properties of water, along with water microflora.

Vectors, pathogens, and hosts each survive and reproduce within certain optimal climatic conditions and changes in these conditions can modify greatly these properties of disease transmission. The most influential climatic factors for vector borne diseases include temperature and precipitation. These factors greatly affect survival and reproduction rate of the vector, time of year and level of vector activity, specifically the biting rate of development and reproduction of the pathogen within the vector (Kovats, 2001).

\section{References}

Ahmed W, Vieritz A, Goonetilleke A. (2010). Health risk from the use of roof-harvested rainwater in southeast Queensland, Australia, as potable or nonpotable water, determined using quantitative microbial risk assessment. Appl Environ Microbiol; 76: 7382-91.

Albritton D. (2001). Technical Summary. In: Climate Change 2001: The Scientific Basis. Contribution of Working Group I to the Third Assessment Report of the Intergovernmental Panel on Climate Change. Cambridge University Press, Cambridge.

Alonso D., Menno J., Bouma M. J., Pascual M. (2011). Epidemic malaria and warmer temperatures in recent decades in an East African highland. Proclamation research Society. 278:1661-69.

Boxall A.B., Hardy A., Beulke S., Boucard T., Burgin L., Falloon P.D, (2009) . Impacts of climate change on indirect human exposure to pathogens and chemicals from agriculture. Environmental Health Perspect; 117(4):508-14.

Callaway T. R, Edrington T. S, Anderson R. C, Byrd J. A, Nisbet D. J. (2008). Gastrointestinal microbial ecology and the safety of our food supply as related to Salmonella. Journal of Animal Science .

Colwell, R .R. (1996). Global climate and infectious disease: the cholera paradigm. Science. 274(5295): 2025- 
2031.

Confalonieri U, Menne B, Akhtar R, Ebi KL, Hauengue M, Kovats RS, Revich B, Woodward A. (2007). Human health. In: Climate Change 2007: Impacts, Adaptation and Vulnerability. Contribution of Working Group II to the Fourth Assessment Report of the Intergovernmental Panel on Climate Change, Parry ML, Canziani OF, Palutikof JP, van der Linden PJ, Hansson CE, Eds. Cambridge University Press, Cambridge, UK. 391-431

Chu Y., Salles C., Tournoud M. G., Got P., Troussellier M., Rodier C. (.2011). Faecal bacterial loads during flood events in Northwestern Mediterranean coastal rivers. Journal of Hydrology 405 (3-4):501-11.

Curriero F. C., Patz J. A., Rose J. B., Lele S. (2001) The association between extreme precipitation and waterborne disease outbreaks in the United States, 1948-1994. American Journa of Public Health 91(8):1194-9

Dhiman R. C., Pahwa S., Dhillon G. P., Dash A. P. (2010). Climate change and threat of vector borne diseases in India: are we prepared? Parasitology Research.;106: 763-773.

D’Souza R.M. (2004). Does ambient temperature affect foodborne disease ? Epidemiology; 15: 86-92.

Ebi K.L. (2006). Climate change and human health impacts in the United States: an update on the results of the U.S. National Assessment. Environmental Health Perspectives; 114: 1318-1324.

Edwards S. J. (2015). Water, Climate Change, Health and Adaptation. Sustainable Development and Environmental Health PAHO/WHO Office for Barbados and the Eastern Caribbean Countries.

European Center for Disease Prevention and Control. (2010). Annual epidemiological report on communicable diseases in Europe. 2009. Stockholm, Sweden: ECDC

Evans C., Monteith D., Cooper D. (2005). Long-term increases in surface water dissolved organic carbon: observations, possible causes and environmental impacts. Environmental Polutionl; 137:55- 71.

.FAO (2008). Climate change: implications for food safety. Food and Agriculture Organization of the United Nations.

Githeko, A. \& Ndegwa, W. (2001). predicting malaria epidemics in the Kenyan highlands using climate data: a tool for decision-makers. Global Change \& Human Health 2: 54-63.

Hilscherova K., Dusek L., Kubik V., Cupr P., Hofman J., Klanova J. (2007) Redistribution of organic pollutants in river sediments and alluvial soils related to major floods. Journal Soil Sedment. 7(3):167 77.

Hoelzer K, Isabel A, Switt M, Wiedmann M. (2011). Animal contact as a source of human non typhoidal salmonellosis. Veternary Research. 42:34.

Hopp M. J., Foley J. A. (2001). Global-scale relationships between climate and the dengue fever vector, Aedes Aegypti. Climate Change. 48:441-463.

Howe AD, Forster S, Morton S, Marshall R, Osborn KS, Wright P, (2002). Cryptosporidium oocysts in a water supply associated with a cryptosporidiosis outbreak. Emerging Infectious Diseases. 8:619-24.

Hoxie N.J., Davis J.P., Vergeront J.M., Nashold R.D., Blair K.A. (1997). Cryptosporidiosis- associated mortality following a massive waterborne outbreak in Milwaukee, Wisconsin. American Journal of Publi Health. 87(12):2032-5.

Hurst C J. (2007). Overview of water microbiology as it relates to public health. In: Hurst CJ, Crawford RL, Garland JL, Lipson DA, Mills AL, Stetzenbach LD (Eds.). Manual of environmental microbiology. Third edition. Washington, DC: ASM Press. p. 219-21.

Hunter P. (2003). Climate change and waterborne and vectorborne disease. Journal of Applied. Microbiology. 94:37-46.

Intergovernmental Panel on Climate Change. (2001). Climate Change 2001: The Scientific Basis; Impacts, Adaptation and Vulnerability; Mitigation (3 volumes). Cambridge University Press, Cambridge.

Josef Y., Matthias G., Christiane H., Ute M., Albert R., Günter K. (2016). Association between the ambient temperature and the occurrence of human Salmonella and Campylobacter infections. Scientific reports.

Kim K. H., Jahan S. A., Kabir E. (2013). A review on human health perspective of air pollution with respect to allergies and asthma. Environmental International. 59:41-52.

Kinney P. L. (2008). Climate change, air quality, and human health. American Journal of Prevention Medical. 35:459 467.

Kistemann T, Claßen T, Koch C, Dangendorf F, Fischeder R, Gebel J. (2002). Microbial load of drinking water reservoir tributaries during extreme rainfall and runoff. Applied Environmental Microbiology. 68(5):2188-97.

Koelle K., Rodo X., Pascual M., Yunus M., Mostafa G. (2005). Refractory periods and climate forcing in cholera dynamics. Nature. 436(7051):696-700.

.Kovats, R.S. (2001). Early effects of climate change: do they include changes in vector-borne disease? Philosophical Transactions of the Royal Society of London Biological Sciences 356(1411): 1057-1068.

Lake I. R, gillespie I. bentham A., G., Nichols G., Lane L., C., Adak G. K. and Threlfalla E. J. (2009). Re evaluation of the impact of temperature and climate change on foodborne illness. Epidemiology of Infection. 137: 15381547.

Lake I. R., Bentham G, Kovats R. S., Nichols G. L. (2005) Effects of weather and river flow on cryptosporidiosis. Journal of Water and Health. 3(4):469-74. 
Lambrechts L., Paaijmans K.P., Fansiria T., Carrington L.B., Kramer L.D (2011). Impact of daily temperature fluctuations on dengue virus transmission by Aedes aegypti. Proclamation of Natural Acadamic Science. USA. 108: 7460-7465.

Lipp E.K., Huq A., Colwell R.R. (2002) Effects of global climate on infectious disease: the cholera model. Clinical Microbiology Revolution. 15(4):757-70.

Liu C., Hofstra N., Franz E. (2013). Impacts of climate change on the microbial safety of pre- harvest leafy green vegetables as indicated by Escherichia coli O157 and Salmonella spp. International Journal of Food Microbiology. 163:119-128.

Luma A. H., Anwar A. and Remata S. R. (2014). Effects of Climate Change on Salmonella Infections. Foodborne Pathogens and Disease Volume 11: 12

Mac Kenzie W.R., Hoxie N.J., Proctor M.E., Gradus M.S., Blair K.A., Peterson D.E. (1994). A massive outbreak in Milwaukee of cryptosporidium infection transmitted through the public water supply. New English Journal of Medicine. 331(3):161-7.

McMichael A.J., Woodruff R.E., Hales S. (2006). Climate change and human health: present and future risks. Lancet; 367: 859-869.

Menne B., Bertollini R. (2000) The health impacts of desertification and drought. Down to Earth 14:4-6.

Menne B. (2011). Impacts of climate change and extreme events on waterborne disease. In: Sinisi L, Aertgeerts R (Ed.). Guidance on water supply and sanitation in extreme weather events. Copenhagen: UNECE/WHO;

Mills J. N., Gage K. L., Khan A. S. (2010). Potential influence of climate change on vector- borne and zoonotic diseases: A review and proposed research plan. International Journal of Health Geography. 9:54.

Nie L, Lindholm O, Braskerud B. (2009). Urban flood management in a changing climate. Journal of Water. 2: 203-13.

Nygard, K., Andersson, Y., Rottingen, J.A., Svensson, A., Lindback, J., Kistemann, T., and Giesecke, J. (2004). Association between environmental risk factors and Campylobacter infections in Sweden. Epidemiologyof Infectious. 132: 317-325.

Patrick M. E., Christiansen L. E., Wainø M. Ethelberg S. Madsen H. and Wegener H. C. (2004). Effects of Climate on Incidence of Campylobacter spp. in Humans and Prevalence in Broiler Flocks in Denmark. Applied and Environmental Microbiology, pp. 7474-7480

Patz J. A., McGeehin M. A., Bernard S.M. (2000). The potential health impacts of climate variability and change for the United States: Executive summary of the report of the health sector of the U.S. National Assessment. Environmental Health Perspective. 108: 367-76.

Patz J. A., Campbell-Lendrum D., Holloway T., Foley J. A. (2005). Impact of regional climate change on human health. Nature. 438: 310-317.

Paz S. (2014). Impact of Temperature Variability on Cholera Incidence in Southeastern Africa, 1971-2006. EcoHealth. 6:340-345,

Rogers D. J. (2006). Randolph SE. Climate change and vector-borne diseases. Advanced. Parasitology. 62:345381.

Rose, J.B. (2001). Climate variability and change in the United States: potential impacts on water- and foodborne diseases caused by microbiologic agents. Environmental Health Perspectives. 2: 211-221.

Rosen B. (2000). Waterborne pathogens in agricultural watersheds. Burlington, Vt.: USDA- NRCS Watershed Institute, University of Vermont.

Semenza J. C., Herbst S., Rechenburg A., Jonathan E. S., Christoph H. O., Schreiber C., And Kistemann T. (2012). Climate Change Impact Assessment of Food- And Waterborne Diseases. Critical Reviews in Environmental Science and Technology, 42:857-890.

Scallan E., Hoekstra R.M., Angulo F. J. (2011). "Foodborne illness acquired in the United States-major pathogens," Emerging Infectious Diseases. 17 (1):7-15.

Singh R.B.K. (2001). The influence of climate variation and change on diarrheal disease in the Pacific Islands. Environmental Health Perspectives; 109: 155-159.

Stephen D. M., Barnett A. G. (2016). Effect of temperature and precipitation on salmonellosis cases in South-East Queensland, Australia: an observational study. BMJ.

Tirado M. C., Clarke R., Jaykus L. A., McQuatters-Gollop A., Frank J. M. (2010). Climate change and food safety: a review. Food Research International. 43:1745-1765.

Wanjala C. L., Waitumbi J., Guofa Zhou G., Githeko A. K. (2011). Identification of malaria transmission and epidemic hotspots in the western Kenya highlands: its application to malaria epidemic prediction. Parasite Vectors. 4:81-87.

Willocks L., Crampin A., Milne L., Seng C., Susman M., Gair R., (1998). A large outbreak of cryptosporidiosis associated with a public water supply from a deep chalk borehole. Communicable Disease and Public Health; 1(4):239-43.

Wilson, M.L. (2001). Ecology and infectious disease. In: Ecosystem change and public health: a global 
perspective, Aron J.L. \& Patz, J.A. (eds). Baltimore, USA, John Hopkins University Press, pp. $283-324$.

World Health Organization. (2008). Protecting health in Europe from climate change. Geneva, Switzerland: World Health Organization

World Health Organization (2012). World Meteorological Organization. Atlas of health and climate. Geneva: WHO, WMO.

Yamamoto N., Urabe K., Takaoka M., Nakazawa K., Gotoh A., Haga M. (2000). Outbreak of cryptosporidiosis after contamination of the public water supply in Saitama Prefecture. Journal of. Japan Association. Infectious Diseases. 74 (6):518-26. 